\title{
Presidential Cycles and Time-Varying Bond-Stock Correlations: \\ Evidence from More than Two Centuries of Data
}

\author{
Riza Demirer ${ }^{*}$ and Rangan Gupta ${ }^{* *}$
}

\section{Highlights}

- We document a presidential cycle effect on stock-bond market correlations.

- Democratic administrations are associated with lower degree of co-movement.

- The negative presidential cycle effect is robust over various sub-samples.

\begin{abstract}
Utilizing a DCC-GARCH model to capture time-varying correlations, we show that Democratic administrations are generally associated with lower degree of co-movement between the stock and government bond returns. The findings are in line with the documented presidential cycle effect on stock market returns and corroborate recent evidence that, when risk aversion is high, agents tend to elect the Democratic Party.
\end{abstract}

Keywords: Conditional correlation, GARCH, Bond and Stock Returns Comovement, US Presidential Cycles

JEL codes: C22, C32, D72, G10, G12

\footnotetext{
* Department of Economics \& Finance, Southern Illinois University Edwardsville, Edwardsville, IL 62026-1102, USA. Email: rdemire@siue.edu.

** Corresponding author. Department of Economics, University of Pretoria, Pretoria, South Africa. Email: rangan.gupta@up.ac.za.
} 


\section{Introduction}

Stock market returns in the United States (US) are found to be significantly higher under Democratic presidents than under Republicans. However, the source of this return gap is unclear. Santa-Clara and Valkanov (2003) dub this phenomenon the "presidential puzzle", after ruling out various potential explanations, including risk-based arguments. Pástor and Veronesi (2017) recently develop a model of political cycles in which the presidential puzzle emerges endogenously. They show theoretically that when risk aversion is high, voters are more likely to elect a Democratic president because they demand more social insurance. On the other hand, when risk aversion is low, a Republican president is likely to be elected, since the voters want to take on more business risk. Therefore, greater aversion under Democrats result in a higher equity risk premium, thus a higher average return. An immediate implication of this theoretical observation is that, since agents have higher risk aversion when Democratic presidents are in power, it is likely that one would expect to see a re-allocation in investment portfolios out of equities towards relatively less risky assets, such as government bonds. As a result, the correlation between returns associated with these two major asset classes is likely to be reduced in magnitude, and possibly, even turn negative due to fund flows in opposite directions. Clearly, this is an issue of high importance for portfolio diversification and risk management.

Against this backdrop, the objective of our study is to analyze the evolution of the correlations between U.S. stock and government bond returns using Engle's (2002) dynamic conditional correlation generalized autoregressive conditional heteroskedasticity (DCC-GARCH) model on monthly data over the historical period of 1791:09-2017:12. Besides accounting for time-varying volatility behavior of the data series, a major advantage of the DCC-GARCH approach is its ability to detect changes in the conditional correlation over time, both in terms of sign and magnitude. Unlike rolling windows (an alternative way to capture time-variation), the proposed measure of correlation does not suffer from the so-called "ghost features", as the effects of a shock are not reflected in $n$ consecutive periods, with $n$ being the window span (Antonakakis et al., 2013). Furthermore, under the DCC-GARCH, there is no need to set a window span, or incur loss of observations, besides not having to conduct subsample estimations. Once the timevarying correlations are obtained, we conduct regression analysis over the full-sample of more 
than two centuries and various sub-samples based on structural break tests and examine the effect of the presidential cycles on the dynamic conditional correlations (DCC).

While there exists a large literature that has analyzed the correlation (and covariance) between bond and stock returns [see, Kollias et al., (2013) and Selmi et al., (forthcoming) for detailed reviews in this regard], and various covariates (ranging from macroeconomic and financial variables to uncertainty and geopolitical risks) have been used to explain the underlying relationship between these two assets, to the best of our knowledge, this is the first paper to not only study the dynamic correlation between stock and bond returns over a period of more than two years, but also relate the same to the presidential cycles in the US. Our findings empirically validate the presidential cycle effect on return correlations based on more than two centuries of historical data and support the suggestion that the presidential cycle effect on financial market returns emerges endogenously in that higher risk aversion during Democratic presidential cycle leads to fund flows into relatively safer assets out of risky counterparts. The remainder of the paper is organized as follows: Section 2 describes the empirical methodology, while Section 3 presents the data used and the empirical findings, with Section 4 concluding the paper.

\section{Methodology}

In order to examine the evolution of co-movements between the government bond and equity returns, we obtain a time-varying measure of correlation based on the dynamic conditional correlation model of Engle (2002). Let $y_{t}=\left[y_{1 t}, y_{2 t}\right]^{\prime}$ be a $2 \times 1$ vector comprising the data series. The conditional mean equations are represented by

$$
A(L) y_{t}=+\varepsilon_{t}, \quad \varepsilon_{t} \mid \Omega_{t-1} \sim N\left(0, H_{t}\right), \text { and } t=1, \ldots, T
$$

where $A$ is a matrix of endogenous variables, $L$ the lag operator and $\varepsilon_{t}$ is the vector of innovations based on the information set, $\Omega$, available at time $t-1$. The $\varepsilon_{t}$ vector has the following conditional variance-covariance matrix

$$
H_{t}=D_{t} R_{t} D_{t}
$$

where $D_{t}=\operatorname{diag} \sqrt{h_{i t}}$ is a $2 \times 2$ matrix containing the time-varying standard deviations obtained from univariate $\operatorname{GARCH}(p, q)$ models as 


$$
h_{i t}=\gamma_{i}+\sum_{p=1}^{P_{i}} \alpha_{i p} \varepsilon_{i t-i p}^{2}+\sum_{q=1}^{Q_{i}} \beta_{i q} h_{i q-q}, \quad \forall i=1,2
$$

The DCC(M,N) model of Engle (2002) comprises the following structure

$$
R_{t}=Q_{t}^{*-1} Q_{t} Q_{t}^{*-1}
$$

where

$$
Q_{t}=\left(1-\sum_{m=1}^{M} a_{m}-\sum_{n=1}^{N} b_{n}\right) \bar{Q}+\sum_{m=1}^{M} a_{m}\left(\varepsilon_{t-m}^{2}\right)+\sum_{n=1}^{N} b_{n} Q_{t-n}
$$

$\bar{Q}$ is the time-invariant variance-covariance matrix retrieved from estimating equation (3), and $Q_{t}^{*}$ is a $2 \times 2$ diagonal matrix comprising the square root of the diagonal elements of $Q_{t}$. Finally, $R_{t}=\rho_{i j_{t}}=\frac{q_{i j, t}}{\sqrt{q_{i i, t} q_{j j, t}}}$ where $i, j=1,2$ is the $2 \times 2$ matrix consisting of the conditional correlations between the government bond and stock market returns, which is our main focus.

\section{Data and Results}

The two main variables of interest in our empirical analysis are the monthly 10-year government bond and equity market returns for the U.S. over the period of 1791:9-2017:12, including 2,716 observations. The stock $(S R)$ and bond $(B R)$ returns are computed as the first-difference of the natural logarithms of the S\&P500 total return index and the 10-year government bond total return index, respectively. The data on both indices are obtained from the Global Financial Database, with the start and end dates purely driven by data availability for each series. Given that we use stock and bond returns, we satisfy the condition of stationary data required for the estimation of the DCC-GARCH approach. ${ }^{1}$ Separately, we obtain data on the presidential cycles from http://www.enchantedlearning.com/history/us/pres/list.shtml. This information is used to create a dummy that captures presidential cycles, taking a value of one for months during which a Democratic president was in office and zero otherwise. ${ }^{2}$

\footnotetext{
${ }^{1}$ Complete details of various unit root tests indicating that both returns series are stationary are available upon request from the authors.

${ }^{2}$ It must be pointed out that there were presidential cycles over which both Democratic and Republican parties were in office together (for example, 1801-1829), for which the dummy variable took the value of one. Also, in years 1791-1801 and 1841-1845, 1849-1853, and 1865-1869, presidents came from Federalist, Whig and National Union parties respectively. For these years, the dummy variable is assigned the value zero.
} 
Table 1: DCC-GARCH model estimates for the period 1791:09 - 2017:12

\begin{tabular}{|c|c|c|}
\hline \multicolumn{3}{|c|}{ Panel A: Conditional mean } \\
\hline & $B R_{t}$ & $S R_{t}$ \\
\hline \multirow[t]{2}{*}{ Cons } & $0.3318 * * *$ & 0.0043 \\
\hline & $(0.0049)$ & $(0.0404)$ \\
\hline \multirow[t]{2}{*}{$B R_{t-1}$} & 0.0109 & $0.1373 * * *$ \\
\hline & $(0.0167)$ & $(0.0200)$ \\
\hline \multirow{2}{*}{$B R_{t-2}$} & $-0.0832 * * *$ & $0.0497 * *$ \\
\hline & $(0.0103)$ & $(0.0232)$ \\
\hline \multirow[t]{2}{*}{$B R_{t-3}$} & $0.0386 * * *$ & 0.0143 \\
\hline & $(0.0072)$ & $(0.0160)$ \\
\hline \multirow{2}{*}{$B R_{t-4}$} & $0.0314 * * *$ & $0.0569^{* *}$ \\
\hline & $(0.0067)$ & $(0.0238)$ \\
\hline \multirow[t]{2}{*}{$B R_{t-5}$} & $-0.0571 * * *$ & $0.0473 * *$ \\
\hline & $(0.0076)$ & $(0.0233)$ \\
\hline \multirow{2}{*}{$B R_{t-6}$} & $0.1152 * * *$ & 0.0065 \\
\hline & $(0.0125)$ & $(0.0227)$ \\
\hline \multirow{2}{*}{$S R_{t-1}$} & $-0.0206 * * *$ & $0.1918 * * *$ \\
\hline & $(0.0020)$ & $(0.0174)$ \\
\hline \multirow[t]{2}{*}{$S R_{t-2}$} & 0.0033 & $-0.0490 * * *$ \\
\hline & $(0.0027)$ & $(0.0167)$ \\
\hline \multirow[t]{2}{*}{$S R_{t-3}$} & $-0.0160 * * *$ & $0.0415^{* *}$ \\
\hline & $(0.0044)$ & $(0.0174)$ \\
\hline \multirow[t]{2}{*}{$S R_{t-4}$} & $-0.0148 * * *$ & -0.0053 \\
\hline & $(0.0024)$ & $(0.0155)$ \\
\hline \multirow[t]{2}{*}{$S R_{t-5}$} & $0.0177 * * *$ & $0.0508 * * *$ \\
\hline & $(0.0020)$ & $(0.0164)$ \\
\hline \multirow[t]{2}{*}{$S R_{t-6}$} & $-0.0264 * * *$ & 0.0111 \\
\hline & $(0.0037)$ & $(0.0166)$ \\
\hline \multicolumn{3}{|c|}{ Panel B: Conditional variance: $H_{t}=\Gamma^{\prime} \Gamma+A^{\prime} \varepsilon_{t-1} \varepsilon_{t-1}^{\prime} A+B^{\prime} H_{t-1} B$} \\
\hline \multirow[t]{2}{*}{$\gamma$} & $0.8030 * * *$ & $0.8714 * * *$ \\
\hline & $(0.0046)$ & $(0.0122)$ \\
\hline \multirow[t]{2}{*}{$\alpha_{1}$} & $0.4219 * * *$ & $0.2487 * * *$ \\
\hline & $(0.0017)$ & $(0.0026)$ \\
\hline \multirow[t]{2}{*}{$\beta_{2}$} & $0.9312 * * *$ & $0.9782 * * *$ \\
\hline & $(0.0034)$ & $(0.0010)$ \\
\hline \multirow[t]{2}{*}{$a$} & $0.0106 * * *$ & \\
\hline & $(0.0014)$ & \\
\hline \multirow[t]{2}{*}{$b$} & $0.9854 * * *$ & \\
\hline & $(0.0023)$ & \\
\hline \multicolumn{3}{|c|}{ Panel C: Misspecification tests } \\
\hline \multirow[t]{2}{*}{$Q(4)$} & 6.0864 & 2.0143 \\
\hline & [0.1928] & [0.7331] \\
\hline \multirow[t]{2}{*}{$Q(8)$} & $13.6538^{*}$ & 5.1228 \\
\hline & [0.0912] & [0.7444] \\
\hline \multirow[t]{2}{*}{$Q^{2}(4)$} & 0.1071 & 3.5665 \\
\hline & [0.9986] & {$[0.4678]$} \\
\hline$Q^{2}(8)$ & 0.2979 & 6.7394 \\
\hline & {$[1.0000]$} & {$[0.5650]$} \\
\hline
\end{tabular}

Note: $B R_{t}$ and $S R_{t}$ denote the government bond returns and real stock market returns, respectively, at time $t .6$ lags in the conditional mean equations were suggested by the Akaike Information Criterion (AIC). $Q(4)$ and $Q^{2}(4)(Q(8)$ and $Q^{2}(8)$ ) are the Ljung-Box $Q$-Statistics on the standardized and squared standardized residuals, respectively, up to 4 (8) lags. Standard Errors are in parentheses and $p$-values are in square brackets. ${ }^{*}, * *$ and $* * *$ denote statistical significance at the $10 \%, 5 \%$ and the $1 \%$ levels, respectively. 
Table 1 reports the results of the DCC model. Panels A and B present the conditional mean and variance results, respectively, while Panel C contains the Ljung-Box Q-Statistics on the standardized and squared standardized residuals up to 4 and 8 lags. The choice of the lag-length of the autoregressive process of the conditional mean, which is equal to six, is based on the Akaike information criterion (AIC) ${ }^{3}$.

According to the conditional mean results reported in Table 1, we find that the past values of government bond and stock market returns in general have a significant effect on the current values of the same. The fifth lag of stock returns significantly increases bond returns (with lags one, three, four and six significantly reducing bond returns), while the first, second, fourth and fifth lags of bond returns increases stock market returns significantly. The conditional variance results reported in the same table support the existence of the GARCH effects found in the series, as the coefficients $\alpha_{1}$ and $\beta_{1}$ are highly significant. Moreover, the coefficients $a$ and $b$ are highly significant, indicating that the correlations between stock market and government bond returns are indeed time-varying, validating the choice of the DCC model to capture the time variation in co-movement. Finally, the model does not suffer from serial correlation in the squared (standardized) residuals, according to the misspecification tests reported in Panel C of Table 1.

Figure 1 presents the DCCs of government bond and stock market returns estimated in Table 1, along with their $95 \%$ confidence intervals, superimposed on the months during which a Democratic president was in power, as indicated by the shaded areas. As seen in Figure 1, it is evident that DCCs between government bond and stock market returns in general are significantly positive over the entire sample period, barring the months of 1792:05-1793:02, 1929:12-1931:10, 1957:06-1962:06, 1966:05-1966:08, 1966:12-1967:01, 1967:03, 2001:10, and 2001:12-2017:12, where the relationship turns significantly negative. The strong degree of significance is highlighted by the very tight confidence bands, to the extent that it cannot be distinguished from the estimate of the DCC. More importantly, visual inspection suggests that the DCC estimates tend to decline during months when a Democratic president was in power,

\footnotetext{
3 The Schwarz information criterion (SIC) suggested an optimal lag of one. However, our results were both quantitatively and qualitatively similar to those reported in the paper, when we obtained the correlation from the DCC-GARCH model with one lag only. Complete details of these results are available upon request from the authors.
} 
with the only exception being the Republican Bush administration during the 2001:01-2008:12 period. Interestingly, this period also coincides with the commodity boom during which the commodity market experienced significant fund flows from financial investors - a phenomenon termed as commodity financialization in the literature (Demirer et al., 2015).

Figure 1: Dynamic conditional correlations between U.S. government bond and stock returns

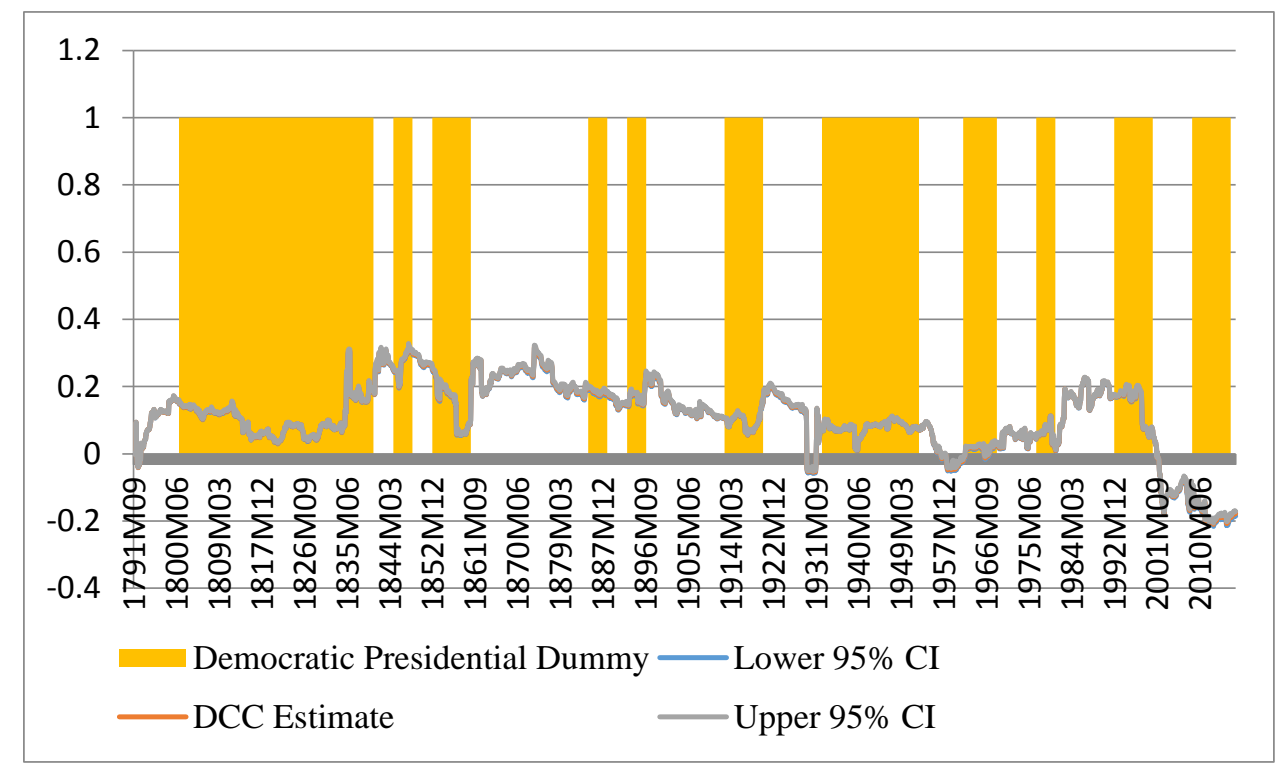

Note: Shaded areas denote Democratic presidential periods.

In order to formally test the presence of a presidential cycle effect on time-varying correlations, we estimate a linear regression model with the underlying DCC as the dependent variable regressed on a constant and the Democratic president dummy. This model is estimated both for the full sample and over six sub-samples (based on five breaks: 1835:06, 1877:10, 1911:09, 1950:03, and 1984:02), as identified by the powerful UDmax and WDmax tests of Bai and Perron (2003), to detect 1 to $M$ structural breaks in the relationship between the DCC and dummy, thus allowing for heterogenous error distributions across the breaks.

The findings reported in Table 2 clearly indicate that there is indeed a presidential cycle effect on the correlations between these two major asset classes. We observe that the DCC is negatively and significantly reduced by the dummy variable capturing periods of Democratic presidents for the full-sample. We also see that the presidential cycle effect is robust in five out of six subsamples, with the effect being insignificant in two of the sub-samples (1791:09-1835:05 and 1950:03-1984:01). The only exception is the sub-sample covering the period of 1877:10- 
1911:08, where the estimated coefficient is positive. However, during this sub-period of 407 months, only two terms (1885-1888 and 1893-1896), i.e. 96 months, were under Democratic presidents, rendering this positive effect for the Democratic dummy not very reliable. Overall, our findings add to the literature on the effect of presidential cycles on stock and bond market returns and further show that such an effect also presents itself in the case of asset correlations. These findings are in fact in line with the suggestion that the presidential cycle effect on financial market returns emerges endogenously in that higher risk aversion during Democratic presidential cycle leads to fund flows into relatively safer assets out of risky counterparts, leading to a decline in the correlation between stocks and government bond market returns.

Table 2: Dynamic Conditional Correlations and the Democratic Presidential Dummy

\begin{tabular}{lll}
\hline Sample Period & Constant & $\theta$ \\
\hline 1791:09-2017:12 & $0.1312 * * *(0.0028)$ & $-0.0414 * * *(0.0040)$ \\
$1791: 09-1835: 05$ & $0.0932 * * *(0.0039)$ & $-0.0027(0.0044)$ \\
$1835: 06-1877: 09$ & $0.2558 * * *(0.0030)$ & $-0.0671 * * *(0.0046)$ \\
$1877: 10-1911: 08$ & $0.1644 * * *(0.0018)$ & $0.0120 * * *(0.0038)$ \\
$1911: 09-1950: 02$ & $0.1188 * * *(0.0039)$ & $-0.0335 * * *(0.0048)$ \\
$1950: 03-1984: 01$ & $0.0442 * * *(0.0030)$ & $-0.0029(0.0046)$ \\
$1984: 02-2017: 12$ & $0.0377 * * *(0.0109)$ & $-0.0520 * * *(0.0159)$ \\
\hline
\end{tabular}

Note: The estimation result is based on a linear regression: $D C C_{t}=$ constant $+\theta^{*}$ Democratic Presidential Dummy ${ }_{t}+$ $u_{t} ; u$ being the regression error normally distributed with zero mean and constant variance. Standard Errors are in parentheses. ${ }^{* * *}$ denote statistical significance at the $1 \%$ level.

\section{Conclusion}

In an attempt to explain the so-called "presidential puzzle" on financial market returns, Pastor and Veronesi (2017) recently develop a theoretical model to show that when risk aversion is high, agents are more likely to elect the Democratic party, as it promises more fiscal redistribution. Higher risk aversion in the market, in turn, results in higher equity premium and higher average stock market returns. If this line of reasoning holds, one would expect that the correlation between stock and government bond returns would be lower during Democratic presidential cycles as these asset classes would experience fund flows in opposite directions, with significant implications for portfolio diversification and risk management. To achieve our objective empirically, we first obtain a measure of time-varying correlations over the monthly period of 1791:09 to 2017:12 using a DCC-GARCH model, and relate the computed correlations to a dummy variable capturing the episodes of Democratic presidents via regression analysis. We 
observe that while, the correlation between these two major asset classes is mostly positive, it does tend to decline when the president is a Democrat, empirically validating the presidential cycle effect on return correlations based on more than two centuries of historical data.

\section{References}

Antonakakis, N., Chatziantoniou, I., and Filis, G. (2013). Dynamic co-movements of stock market returns, implied volatility and policy uncertainty. Economics Letters, 120(1), 8792.

Bai, J. and Perron, P. (2003). Computation and analysis of multiple structural change models. Journal of Applied Econometrics, 18(1), 1-22.

Demirer, R., D. Lien and H. Lee (2015). Does the stock market drive herd behavior in commodity futures markets? International Review of Financial Analysis 39, 32-44.

Engle, R. (2002). Dynamic Conditional Correlation: A Simple Class of Multivariate Generalized Autoregressive Conditional Heteroskedasticity Models. Journal of Business \& Economic Statistics, 20(3), 339-50.

Kollias, C., Papadamou, S., and Arvanitis, V. (2013). Does terrorism affect the stock-bond covariance? Evidence from European Countries. Southern Economic Journal, 79(4), 832848.

Pástor, L., and Veronesi, P. (2017). Political Cycles and Stock Returns. National Bureau of Economic Research (NBER) Working Paper No. 23184.

Santa-Clara, Pedro, and Rossen Valkanov, R. (2003). The presidential puzzle: Political cycles and the stock market, Journal of Finance, 58, 1841-1872.

Selmi, R., Kollias, C., Papadamou, S., and Gupta, R. (Forthcoming). The stock-bond nexus and investors' behavior in mature and emerging markets: evidence from long-term historical data. Studies in Economics and Finance, Special Issue: Behavioral Economics and Behavioral Finance. 